\title{
Author Correction: Overexpression of Aiolos promotes epithelial- mesenchymal transition and cancer stem cell-like properties in lung cancer cells
}

\author{
Jung-Jyh Hung, Ying-Shiun Kao, Chi-Hung Huang \& Wen-Hu Hsu \\ Correction to: Scientific Reports https://doi.org/10.1038/s41598-019-39545-Z, published online 28 February 2019 \\ In the original version of this Article, Drs Hung and Kao were incorrectly listed as equally contributing authors. \\ This has now been corrected in the original HTML and PDF versions of the paper, and in the accompanying \\ Supplementary Information.
}

Additionally, the Acknowledgements section in the original version of this Article was incomplete.

"The authors are grateful to Division of Experimental Surgery, Department of Surgery, Taipei Veterans General Hospital, Taipei, Taiwan, for technical assistance. We would like to thank Biobank of NHRI for providing the tissue samples and related clinical data (all are anonymous) for our research. NHRI Biobank is supported by grants from Ministry of Science and Technology and National Health Research Institutes, Taiwan. The authors are also grateful to Dr. Kou-Juey Wu of China Medical University, Taichung, Taiwan, Dr. Shiu-Feng Huang of NHRI, Miaoli, Taiwan, and Dr. Wen-Juei Jeng of Chang-Gung Memorial Hospital, Taoyuan, Taiwan for their contribution to this article."

now reads:

"The authors are grateful to Division of Experimental Surgery, Department of Surgery, Taipei Veterans General Hospital, Taipei, Taiwan, for technical assistance. We would like to thank Biobank of NHRI for providing the tissue samples and related clinical data (all are anonymous) for our research. NHRI Biobank is supported by grants from Ministry of Science and Technology and National Health Research Institutes, Taiwan. The authors are also grateful to Dr. Kou-Juey Wu of China Medical University, Taichung, Taiwan, Dr. Shiu-Feng Huang of NHRI, Miaoli, Taiwan, and Dr. Wen-Juei Jeng of Chang-Gung Memorial Hospital, Taoyuan, Taiwan for their contribution to this article.

This work was supported in part by Ministry of Science and Technology (MOST 107-2314-B-010-062; J-.J.H.), the Higher Education Sprout Project by the Ministry of Education (MOE) in Taiwan (107AC-D970; J-.J.H.), the National Yang-Ming University-Far Eastern Memorial Hospital Joint Research Program (107DN10 and 108DN14; J-.J.H), Taipei Veterans General Hospital (V107C-149 and V108C-199; J-.J.H.), the Taipei Veterans General Hospital-National Yang-Ming University-Excellent Physician Scientists Cultivation Program (107-V-B079; J-.J.H.), Yen Tjing Ling Medical Foundation (CI-106-10 and CI-107-15; J-.J.H.), Li-Yang Sheen Medical Education Memorial Foundation (J-.J.H. and W-.H.H.)." 
(c) (i) Open Access This article is licensed under a Creative Commons Attribution 4.0 International License, which permits use, sharing, adaptation, distribution and reproduction in any medium or format, as long as you give appropriate credit to the original author(s) and the source, provide a link to the Creative Commons license, and indicate if changes were made. The images or other third party material in this article are included in the article's Creative Commons license, unless indicated otherwise in a credit line to the material. If material is not included in the article's Creative Commons license and your intended use is not permitted by statutory regulation or exceeds the permitted use, you will need to obtain permission directly from the copyright holder. To view a copy of this license, visit http://creativecommons.org/licenses/by/4.0/.

(C) The Author(s) 2020 